\title{
Editorial: Using Ecological Models to Support and Shape Environmental Policy Decisions
}

\author{
Chiara Piroddi ${ }^{1 *}$, Johanna J. Heymans ${ }^{2}$, Diego Macias ${ }^{1,3}$, Marilaure Gregoire ${ }^{4}$ and \\ Howard Townsend ${ }^{5}$ \\ ${ }^{1}$ European Commission, Joint Research Centre (JRC), Ispra, Italy, ${ }^{2}$ European Marine Board, Ostend, Belgium, ${ }^{3}$ Consejo \\ Superior de Investigaciones Cientificas, Instituto de Ciencias Marinas de Andalucia (ICMAN-CSIC), Cadiz, Spain, \\ ${ }^{4}$ Department of Astrophysics, MAST-FOCUS, Geophysics and Oceanography, University of Liége, Liége, Belgium, ${ }^{5}$ National \\ Marine Fisheries Service National Oceanic and Atmospheric Administration (NOAA), Maryland, MD, United States
}

Keywords: operational models, indicators, decision-making, marine and coastal environment, stakeholders

\author{
Editorial on the Research Topic
}

Using Ecological Models to Support and Shape Environmental Policy Decisions

\section{INTRODUCTION}

Marine and coastal ecosystems are directly or indirectly affected by human activities (Von Glasow et al., 2013; Halpern et al., 2019; He and Silliman, 2019; O'hara et al., 2021). Because of their complexity, predicting the effects of regulations and management measures on these ecosystems has been a challenging task (Leslie and Mcleod, 2007; Ruckelshaus et al., 2008; Link et al.,

\section{OPEN ACCESS}

Edited and reviewed by:

Angel Borja,

Technological Center Expert in Marine and Food Innovation (AZTI), Spain

${ }^{*}$ Correspondence: Chiara Piroddi chiara.piroddi@ec.europa.eu

Specialty section: This article was submitted to Marine Ecosystem Ecology, a section of the journal

Frontiers in Marine Science

Received: 15 November 2021 Accepted: 29 November 2021

Published: 23 December 2021

Citation:

Piroddi C, Heymans JJ, Macias D, Gregoire $M$ and Townsend $H$ (2021) Editorial: Using Ecological Models to

Support and Shape Environmental Policy Decisions.

Front. Mar. Sci. 8:815313. doi: 10.3389/fmars.2021.815313 2018; Stephenson et al., 2018). Ecological and socio-ecological models have been recognized to be essential for addressing this issue (Heymans et al., 2018, 2020). These tools can provide an integrative image of key mechanisms and processes at different scales (e.g., from coastal to basin scales) and hierarchical levels (e.g., individuals, populations, communities, and ecosystems) and can be used to explore the consequences of alternative policies or management scenarios (Piroddi et al., 2015; Lynam et al., 2016; Holsman et al., 2017; Smith et al., 2017). Such models have long been used and developed in academic and research settings, but not operationally. More recently they have been used as heuristic tools for policy and management, e.g., to understand general patterns in ecosystem structure and functioning, or for qualitative assessment of the impact of single or multiple pressures on selected species/functional groups (Punde et al., 2017; Ostlaender et al., 2019; Townsend et al., 2019; Link and Marshak, 2021). These types of models have a great potential to directly underpin policies and management decisions, and this potential is beginning to be realized.

This Research Topic showcases recent advancements in modeling tools to directly support environmental management and policies for the sustainable use of coastal and ocean resources. The geographic scope covers coasts, enclosed seas and open oceans, around Europe and the USA This collection of 27 articles highlights the types of models currently being used, the policies and environmental aspects covered, as well as gaps and actions needed to better link models and policies for improving the management and the restoration of our oceans.

\section{FISHERY AND CLIMATE}

This Research Topic highlights that fisheries and associated regulations dominate the bulk of the models used to advise environmental policies. In fact, of the 27 articles, $\sim 41 \%$ were related to modeling and assessing fishing pressure on specific compartments of the ecosystem; an extra $\sim 15 \%$ 
modeled the impact of fishing in combination with changes in climate/environment, while climate on its own represented $\sim 4 \%$ of the accepted papers.

Most of the modeling effort to support fisheries policy is concentrated in the USA, and most of the papers point to the use of coupled and/or ensemble of models to better support/advise fisheries management. For example, Reum et al. reviewed the importance of using multispecies model ensembles (MMEs) to address fisheries management in the Northwest Atlantic Coastal Shelf; Gulf of Mexico; and the California Current. Major conclusions drawn from this review were: 1) the need to have well-defined procedures for review and uptake of information from MMEs to advise fishery management decision-making bodies, as happens for single-species stock assessment models; 2) an ensemble model suite improve the credibility of multispecies models, building confidence in the absence of quantitative treatments; and 3) involvement of a diverse set of stakeholders at an early stage of model development ensures the utility of the models and ensemble in a policy context.

Multi models (from single- and multi-species stock assessment to more complex food web approaches) have been also described by Anstead et al., who reviewed the history of Atlantic menhaden management on the East Coast of the USA and the development and implementation of the ecosystem approach to forage fish management. Drew et al. showed the practical use of these MMEs (from less to more complex models) to evaluate the trade-offs between the harvest of Atlantic menhaden and ecosystem management objectives. Less complex models were relatively easier to implement and update, but lacked key elements needed to manage multiple species simultaneously. By contrast, more complex models required a wider array of data and were more difficult to update within the current management time-frames, but produced a more useful framework for managers. The authors concluded that the food-web model, Ecopath with Ecosim (EwE), coupled with the existing single-species assessment model, was most appropriate for use in management decisions. Further details on this particular model and approach were presented in Chagaris et al. and Howell et al. Although most of these examples are from the USA, the integration of an ecosystem model into the single-species assessment and management framework was also shown in Europe, for the Irish Sea ecosystem (Bentley et al.) again using the EwE software.

To test fishery harvest rules, Kaplan et al. showed the use of end to end models (Atlantis) in the California Current, and Nordic-Barents Seas, addressing explicitly the linkage between predators and prey and between the forage needs of predators and fisheries. The results highlighted that there was an increase in catch variability when fishing mortality rates were linked to prey biomass (zooplankton). In addition, when there was an increase in fishing and a decrease in productivity (zooplankton), strong ecosystem effects on other species could be expected, such as changes in phytoplankton abundance and subsequent effects on epibenthos, zooplankton and other primary producers. Overall, these results demonstrated the usefulness of explicitly incorporating ecosystem concerns within fisheries management to better simulate and address environmental policy questions.
Management strategy evaluation (MSE) was used by Smith et al. to compare static and dynamic fishing closures for the drift-gillnet swordfish fishery in California to reduce leatherback turtles bycatch. This study showed that static and dynamic closures can each play a role in bycatch reduction, but dynamic closures are more effective for species with dynamic habitat associations. In addition, the authors recommended that for highly distributed species like sea turtles, spatial closures may work better with the implementation of other mitigation tools such as effort control, gear selectivity and bycatch quotas.

Kaplan et al. also used MSE to show how and why MSE is continuing to grow from a single species approach to multi-species and ecosystem-based management (EBM). They highlighted case studies from the USA related to fisheries regulations and climate, emphasizing methods, tool development, and lessons learned that are relevant beyond the USA, and the benefits relative to single species MSE approaches.

Szymkowiak and Rhodes-Reese applied a coupled socioecological framework on the sablefish fishery in Alaska to examine which strategies fishermen use to adapt ecosystems conditions. By coupling quantitative indicators and a qualitative network model, they demonstrated how adaptive strategies could be evaluated to capture the multi-faceted well-being effects of how fishers adapt to ecosystem changing conditions. Coupled socio-ecological models, as shown in this study, could elevate the inclusion of human adaptive behaviors, providing a framework that aims to mitigate the adverse effects on both the fishers and the resources by facilitating the mixture of adaptive strategies that maximizes desired well-being outcomes.

Kasperski et al. assessed the state of coupled social-ecological models (SES) in support of the ecosystem based fisheries management approach in the USA. They found that for a model to provide useful strategic or tactical advice, it should only be coupled to the degree necessary to understand the importance of system dynamics/responses and to create management-relevant performance metrics or potential risks from (in) action. The main takeaway message from this study was the key role of "timing" in management uptake and successful coupling. Early engagement between disciplines, and even across sub-disciplines, could ensure the broadest range of questions can be addressed within a management timeline.

Tommasi et al. presented a case study from the West Coast of the USA, showcasing a process to identify management priorities, coming from stakeholders' comments. These priorities were then used to assess potential ecosystem models and analyses that could help to address the policy concerns and identify gaps in existing ecosystem models and analyses that limit their utility to the management process. This is one of the few papers that presented a concrete blueprint for matching models to management needs in a specific policy context.

The only study from the Indian Ocean (Zanzibar) showed the use of a Bayesian hierarchical species distribution modeling approach to identify potential conservation areas for commercially important species, and to better advise local fishing communities on their spatio-temporal decision-making process (Rehren et al.). As highlighted in this paper, this type of approach is particularly valuable for the operability of spatial 
management of small-scale fisheries, which normally suffer from a lack of long-term information and fisheries independent data.

In Europe, in Limfjorden (Denmark), Pastor et al. used a sediment transport model to show the impact that mussel dredging has on sedimentary processes, through resuspension of sediment particles, and potentially on eelgrass growth due to a reduction in water clarity. The results showed that shellfish fishing intensity and frequency have minimal effects on light conditions for eelgrass. However, they suggested that management plans for areas with co-occurring dredging activities and seagrass beds should limit the daily number of dredging activities allowed, and spread them over weeks and months to obtain a more sporadic effect on light conditions.

On the combined impact of fishing and changes in climate, Whitehouse et al. investigated how forecasted climate change and fisheries management scenarios may interact to produce different outcomes for commercial species and the eastern Bering Sea food web. In particular, using a modeling framework that linked/coupled a global earth system, hydrodynamicbiogeochemical, food web and fisheries models, they examined how population dynamics, food web structure, and fishery catches may change in the eastern Bering Sea under climate change. This study aimed to support fisheries managers by providing projections of stock status and ecosystem conditions that can inform guidance on the long-term impacts of climate change and fisheries.

Finally, Kearney et al. highlighted that despite the increasingly need and use of climate change projections for marine resources management strategies, scientists and managers should carefully understand the differences among global Earth System Models (ESMs) in relation to key processes, resolution, etc. The authors provided a summary of some key points marine resources endusers may need to consider when using the biogeochemical model output for marine resources policy strategies.

\section{COASTAL AND OFFSHORE DEVELOPMENT AND RESTORATION}

Coastal and offshore development and restoration models to support management plans represent $\sim 19 \%$ of the articles of this Research Topic. The studies were from the USA (Louisiana) and Europe (East Atlantic and North Sea) and tackled two different aspects of coastal/offshore developments and restorations. In Louisiana, de Mutsert et al. used a hydrological model coupled to a marine food web model in coastal/estuarine areas to evaluate the effects of a large-scale coastal restoration plan on the biomass and distribution of fisheries species. To understand the effects of climate change, simulations also included sea level rise scenarios. Simulation output showed that the plan mostly resulted in increases in species biomass, but that the outcomes were species-specific and basin-specific. The specific sea level rise scenarios affected the amount of wetland habitat maintained, and subsequently the biomass of species depending on that habitat. This work filled an important gap in the literature by evaluating landscape-scale impacts on estuarine food webs and changes in species biomass and distributions in response to environmental changes. By making this type of information available to resource managers, precautionary measures of ecosystem management and adaptation can be implemented.

Still in Louisiana, Barataria Bay, Lewis et al. showed the use of ensemble and coupled marine ecosystem models to inform resource managers in their assessment of the ecological effects of a large-scale marsh restoration project. Multiple models indicated that the food web was resilient to disturbance because of a detritus energy reserve, and because the consumer biomass consisted mostly of low tropic level and high turnover species. This information provided ecosystem-level information to decision-makers for assessing possible basin-scale impacts of a proposed large-scale restoration project on fish and shellfish resources.

In Europe, Serpetti et al. coupled a food web model with a hydrodynamic-sediment tracking model to assess the impacts of Multi-Purpose Platforms (MPPs) on the West Coast of Scotland. These MPPs comprise offshore wind turbines co-located with a fish farm in the surrounding ecosystem. Results showed high sensitivity to changes for bottom-up drivers, such as primary producers and detritus, with potential impact on pelagic and benthic consumers through the food web. The authors also discussed the potential use of this type of modeling approach to support marine spatial planning and the impact that these results might have for EU policies.

In the North Sea, the impact of Offshore Wind Farms (OWFs) on the environment (through filtration of the water column and fecal pellets production by blue mussel) of the Belgian Coastal Zone, was assessed by Ivanov et al. who used a coupled hydrodynamic-sediment transport model. The authors showed that the spatial distribution and extent of the impact in terms of organic and mineral particles fluxes to the bottom were determined by the local hydrodynamics (e.g., tidal and residual currents, mesoscale gyres). Overall, the footprint of the OWF on the total carbon deposition went beyond the study area, and was particularly high within $2-5 \mathrm{~km}$ around the turbine foundation and extends several kilometers away. Different scenarios of design of a future OWFs on a "nature protection" region were assessed and recommendations for the placement of wind turbines were provided.

In a companion paper, the consequences of this altered distribution of the carbon flux was further investigated by De Borger et al., using a hydrodynamic-biogeochemical model. Their results showed that sediments in OWFs became sites of intense organic carbon mineralization, with an average increase in carbon preservation in the sediment. This work provides a first estimate of the scale over which offshore windfarms affect sedimentary nutrient cycling, and indicates that sediment biogeochemistry should also be added to the list of ecosystem effects that need to be taken into consideration in the decisionmaking processes related to OWF placement or dismantling.

\section{EUTROPHICATION AND POLLUTANTS}

Of the articles published in this Research Topic, $\sim 15 \%$ tackled the modeling to support policies to deal with eutrophication $(\sim 11 \%)$ 
and plastic pollution $(\sim 4 \%)$, and all of these were conducted in Europe. In all instances, coupled and ensemble models were the tools utilized to advise policy decisions. For example, Stegert et al. assessed the historical eutrophication state of the North Sea using two coupled physical-biogeochemical models. This was done to evaluate the degree of methodological uncertainties and the reliability of the model-based reconstruction, for example, the impact of boundary conditions, model formulations and natural variability. Results showed that the quality of river forcing dominated model variability in coastal regions while in most of the offshore regions, natural variability dominated. In some specific areas, the difference of answers given by the models dominated the variability. Hence, the authors recommended using a larger number of models, which will provide a more robust estimate, even though the validation efforts will be consequent.

A multi-model assessment was also the approach utilized by Friedland et al., who used up to five coupled hydrodynamicbiogeochemical models to assess the impact of realistic nutrient load reductions (improved management of agriculture and wastewater treatment) from European river systems on the biogeochemistry. Their results showed that in nearly all marine regions, riverine load reductions would lead to reduced nutrient concentrations in the marine environment. In addition, model ensemble displayed strong consistency and robustness, as most, if not all models, indicated improvements in the same areas. Piroddi et al. coupled the hydrodynamic-biogeochemical models of Friedland et al. with 14 High Trophic Level models, covering almost all the EU seas, to assess the impact of these nutrient load reductions on the higher trophic level component of the European marine ecosystems. Their results showed that nutrient reduction measures would not have a significant impact on the structure and function of European regional seas. However, coastal and shelf areas will be more sensitive to environmental changes than large regional and sub-regional ecosystems that also include open seas.

The modeling of pollutants such as microplastics was presented by Van der Molen et al. who used a coupled hydrodynamic-particle tracking model to investigate the differences in dispersal and accumulation of microplastics in the North Sea. Their results showed that floating particles could accumulate temporarily on salinity fronts and in gyres, and were deposited predominantly on west-facing beaches. These outcomes are relevant for the development of environmental legislation and management of microplastics under EU policies.

\section{POLICY-MODELING INTERFACE}

Another important aspect of modeling to support policies is related to the way the results are communicated to decisionmakers/stakeholder. Steenbeek et al. developed an approach that connects an ecosystem model with a game engine for realtime communication and visualization of scientific results. The approach, called OceanViz, focused on communicating scientific data to non-scientific audiences to foster dialogue, offering experimental, immersive approaches to visualizing complex ecosystems whilst avoiding information overload.

On the other hand, Quemmerais-Amice et al. developed a technical and methodological approach to map the risk of cumulative effects on benthic habitats, using the French continental shelf as case study. This tool [built using Spatial Query Language (SQL), Geographic Information System (GIS) and $R$ ] illustrated the feasibility of mapping the risk of cumulative effects on benthic habitats, showing confidence index and variability associated with the analysis. This demonstrator contributes to the concrete implementation of the cumulative effect assessment concept and decision support tools needed within the framework of European policies.

\section{DISCUSSION}

The type of models used to support environmental policies were either coupled $(\sim 33 \%)$, multi model ensembles $(\sim 26 \%)$, both coupled and ensembles $(\sim 15 \%)$, or single models $(\sim 30 \%)$. When coupling models, hydrodynamic-biogeochemical or -sediment transport models, linked (or not) with food web models, were the most numerous. Conversely, of the ensembles, multispecies models (e.g., stock assessment, food web, species distribution, end to end, and statistical models) constituted the majority of the models. Among single models (not coupled or in an ensemble), food webs, MSE, Bayesian, end to end, were used to support fisheries related policies while gaming tool and a DPSIR (Drivers, Pressures, State, Impact and Response; Patrício et al., 2016) framework were used for the modeling-policy interface. Socio-economic-ecological modeling tools were underrepresented $(\sim 7 \%)$. This constitutes the main area where future work is needed, as managing resources is more about managing people, and therefore the links between social/economic and ecological systems are critical if we want to use these tools for ecosystem-based management of our natural resources.

The policies addressed in these studies referred to EU or USA policies, highlighting a lack of models used to address/support broader international policies like the Convention on Biological Diversity (CBD) or the United Nation's sustainable development goals (SDGs), although the majority of indicators/output produced by these tools could be linked to those if needed. While few attempts exist in the literature on the use of marine modeling tools for both CBD and SDG (e.g., Levy and Ban, 2013; Allen et al., 2016), more effort should be put in place to better link national and international policies with available modeling outputs.

Most of the case studies presented in this Research Topic occurred either in Europe or in the USA, with only one exception (Zanzibar, Indian Ocean), showing a lack of studies in this collection on using modeling tools in other parts of the world. This is also pointed out by Heymans et al. (2020) in a paper that highlights the ecosystems modeling needed for the UN Decade of Ocean Science for Sustainable Development. While European studies seem to cover a wider spectrum of environmental pressures/policies mainly driven by European policies such as Marine Strategy Framework Directive/Blue 
Economy and more broadly the EU Green Deal, studies in the USA were mainly dominated by modeling fishing to address fisheries regulation/policy issues.

Overall, this collection of articles emphasize that coupled and/or multi model ensembles are the most utilized tools to answer policy questions. The use of coupled and model ensembles have been recognized to produce more robust and consistent model results, substantially decreasing uncertainties in the scenario outcomes and improving the credibility of the models when advising decision makers. Another important message that emerged from this Research Topic is the need to involve stakeholders in the modeling process from the start. Stakeholders need to be there during the development/implementation/scenarios process, to ensure the utility of these models for management decisions. The co-design of these tools with stakeholders enables better credibility of the models and gives buy-in to the ultimate outcomes that are predicted by the models. Not all the models presented here followed this procedure but they highlighted the need to engage with stakeholders.

The future for applying ecological models to ecosystembased management holds many opportunities (Borja et al., 2020). Fisheries management is a major driver for developing ecological models. Climate is becoming a major driver for model development. As ecosystem considerations continue to be addressed for fisheries and with increasing calls to address climate change, one might expect that this will increase the development and application of ecological models for marine

\section{REFERENCES}

Allen, C., Metternicht, G., and Wiedmann, T. (2016). National pathways to the Sustainable Development Goals (SDGs): a comparative review of scenario modelling tools. Environ. Sci. Policy 66, 199-207. doi: 10.1016/j.envsci.2016.0 9.008

Borja, A., Andersen, J. H., Arvanitidis, C. D., Basset, A., Buhl-Mortensen, L., Carvalho, S., et al. (2020). Past and future grand challenges in marine ecosystem ecology. Front. Mar. Sci. 7:362. doi: 10.3389/fmars.2020.00362

Fulton, E. A. (2010). Approaches to end-to-end ecosystem models. J. Mar. Syst. 81, 171-183. doi: 10.1016/j.jmarsys.2009.12.012

Halpern, B. S., Frazier, M., Afflerbach, J., Lowndes, J. S., Micheli, F., O'hara, C., et al. (2019). Recent pace of change in human impact on the world's ocean. Sci. Rep. 9:11609. doi: 10.1038/s41598-019-47201-9

He, Q., and Silliman, B. R. (2019). Climate change, human impacts, and coastal ecosystems in the anthropocene. Curr. Biol. 29, R1021-R1035. doi: 10.1016/j.cub.2019.08.042

Heymans, J. J., Bundy, A., Christensen, V., Coll, M., De Mutsert, K., Fulton, E. A., et al. (2020). The ocean decade: a true ecosystem modeling challenge. Front. Mar. Sci. 7:554573. doi: 10.3389/fmars.2020.554573

Heymans, J. J., Skogen, M., Schrum, C., and Solidoro, C. (2018). "Enhancing Europe's capability in marine ecosystem modelling for societal benefit," in European Marine Board Future Science Brief, eds K. E. Larkin, J. Coopman, A. Muñiz Piniella, P. Kellett, C. Simon, C. Rundt, C. Viegas, and J. J. Heymans (Oostende: European Marine Board), 32.

Holsman, K., Samhouri, J. F., Cook, G., Hazen, E., Olsen, E., Dillard, M., et al. (2017). An ecosystem-based approach to marine risk assessment. Ecosyst. Health Sustain. 3:e01256. doi: 10.1002/ehs2.1256

Leslie, H. M., and Mcleod, K. L. (2007). Confronting the challenges of implementing marine ecosystem-based management. Front. Ecol. Environ. 5, 540-548. doi: 10.1890/060093 ecosystem-based management. In addition, Link (2010) noted the need for multiple model ensembles to deal with model uncertainty for ecosystem-based management. The articles in this collection (and references therein) indicate that this is becoming a more regular practice.

We note a dearth of end to end modeling sensu (Fulton, 2010; Rose, 2012), in this collection. More holistic models may be important for addressing broader marine EBM trade-offs and for incorporating climate as an ecosystem driver. Thought end to end modeling is limited in this collection, model coupling is demonstrated throughout with comprehensive overview articles on coupling global scale oceanographic models and ecological models (Kearney et al.) and coupling socioeconomic and ecological models (Kasperski et al.). These layout good approaches for coupling models that would enable end to end modeling. In addition, these approaches will be important for modeling climate changes scenarios. Additionally, coupling socioeconomic and ecological models will be useful for future stakeholder engagement and potentially for model co-design processes with stakeholders and policy makers, as has previously been highlighted by Heymans et al. (2018) for European policy makers.

\section{AUTHOR CONTRIBUTIONS}

All authors listed have made a substantial, direct, and intellectual contribution to the work and approved it for publication.

Levy, J. S., and Ban, N. C. (2013). A method for incorporating climate change modelling into marine conservation planning: an Indo-west Pacific example. Mar. Policy 38, 16-24. doi: 10.1016/j.marpol.2012.05.015

Link, J. (2010). Ecosystem Based Fisheries Management: Confronting Tradeofs. New York, NY: Cambridge University Press.

Link, J. S., Dickey-Collas, M., Rudd, M. A., Mclaughlin, R., Macdonald, N. M., Thiele, T., et al. (2018). Clarifying mandates for marine ecosystem-based management. ICES J. Mar. Sci. 76, 41-44. doi: 10.1093/icesjms/fsy169

Link, J. S., and Marshak, A. R. (2021). Ecosystem-Based Fisheries Management: Progress, Importance, and Impacts in the United States. Oxford: Oxford University Press.

Lynam, C. P., Uusitalo, L., Patrício, J., Piroddi, C., Queirós, A. M., Teixeira, H., et al. (2016). Uses of innovative modeling tools within the implementation of the Marine Strategy Framework Directive. Front. Mar. Sci. 3:182. doi: 10.3389/fmars.2016.0 0182

O'hara, C. C., Melanie, F., M., and Halpern, B.S. (2021). At-risk marine biodiversity faces extensive, expanding, and intensifying human impacts. Science 372, 84-87. doi: 10.1126/science.abe6731

Ostlaender, N., Acs, S., Listorti, G., Hardy, M., Ghirimoldi, G., Hradec, J., et al. (2019). Modelling Inventory and Knowledge Management System of the European Commission (MIDAS). Luxembourg: Publications Office of the European Union.

Patrício, J., Elliott, M., Mazik, K., Papadopoulou, K.-N., and Smith, C. J. (2016). DPSIR-two decades of trying to develop a unifying framework for marine environmental management? Front. Mar. Sci. 3:177. doi: $10.3389 /$ fmars.2016.00177

Piroddi, C., Teixeira, H., Lynam, C., Smith, C., Alvarez, M., Mazik, K., et al. (2015). Using ecosystem models to assess biodiversity indicators in support of the EU Marine strategy framework directive. Ecol. Indic. 58, 175-191. doi: 10.1016/j.ecolind.2015.05.037 
Punde, S. P., Laws, R. J., Bohensky, E. L., Skewes, T. D., Bustamante, R. H., and Hockings, M. (2017). Opportunities for modelling tools to support management decision-making in Australian Marine Parks. Austr. J. Mar. Ocean Affairs 9, 107-119. doi: 10.1080/18366503.2017.1279860

Rose, K. A. (2012). End-to-end models for marine ecosystems: are we on the precipice of a significant advance or just putting lipstick on a pig? Sci. Mar. 76, 195-201. doi: 10.3989/scimar.03574.20B

Ruckelshaus, M., Klinger, T., Knowlton, N., and Demaster, D. P. (2008). Marine ecosystem-based management in practice: scientific and governance challenges. Bioscience 58, 53-63. doi: 10.1641/B580110

Smith, D. C., Fulton, E. A., Apfel, P., Cresswell, I. D., Gillanders, B. M., Haward, M., et al. (2017). Implementing marine ecosystem-based management: lessons from Australia. ICES J. Mar. Sci. 74, 1990-2003. doi: 10.1093/icesjms/fs $\mathrm{x} 113$

Stephenson, R. L., Paul, S., Wiber, M., Angel, E., Benson, A. J., Charles, A., et al. (2018). Evaluating and implementing social-ecological systems: a comprehensive approach to sustainable fisheries. Fish Fish. 19, 853-873. doi: 10.1111/faf.1 2296

Townsend, H., Harvey, C. J., Dereynier, Y., Davis, D., Zador, S. G., Gaichas, S., et al. (2019). Progress on implementing ecosystem-based fisheries management in the united states through the use of ecosystem models and analysis. Front. Mar. Sci. 6:641. doi: 10.3389/fmars.2019.00641
Von Glasow, R., Jickells, T. D., Baklanov, A., Carmichael, G. R., Church, T. M., Gallardo, L., et al. (2013). Megacities and Large Urban Agglomerations in the Coastal Zone: Interactions between atmosphere, land, and marine ecosystems. Ambio 42, 13-28. doi: 10.1007/s13280-012-0343-9

Conflict of Interest: The authors declare that the research was conducted in the absence of any commercial or financial relationships that could be construed as a potential conflict of interest.

Publisher's Note: All claims expressed in this article are solely those of the authors and do not necessarily represent those of their affiliated organizations, or those of the publisher, the editors and the reviewers. Any product that may be evaluated in this article, or claim that may be made by its manufacturer, is not guaranteed or endorsed by the publisher.

Copyright (c) 2021 Piroddi, Heymans, Macias, Gregoire and Townsend. This is an open-access article distributed under the terms of the Creative Commons Attribution License (CC BY). The use, distribution or reproduction in other forums is permitted, provided the original author(s) and the copyright owner(s) are credited and that the original publication in this journal is cited, in accordance with accepted academic practice. No use, distribution or reproduction is permitted which does not comply with these terms. 